\title{
COLONIALITY AND ISLANDS
}

[Received August 18th 2019; accepted 22nd 2019 - DOI: 10.21463/shima.13.2.03]

\section{Macarena Gómez-Barris}

\author{
Pratt Institute, New York <mgomezba@pratt.edu> \\ May Joseph
}

Pratt Institute, New York <mjoseph@pratt.edu>

\begin{abstract}
In this introduction to this theme issue of Shima on Coloniality and Islands we lay out the specific theoretical significance and historical importance of decolonial approaches to island studies. Using a decolonial and praxis-oriented framework, we propose a cross-current, Indigenous centred, and trans-oceanic study as the centre of a comparative archipelago studies that operates within a decolonial and postcolonial framework. Considering that archipelagos challenge continental thinking, this issue of Shima attempts to merge multiple sea frameworks and spatialities to present a series of interwoven, striated and interdependent series of island knowledges and the methodologies.
\end{abstract}

This project is an intra-oceanic excursion. It emerges out of an encounter between two island researchers, Macarena Gómez-Barris and May Joseph. Gómez-Barris's work on the extractive zones of the Latin American archipelagoes along the Pacific Ocean and more recent work on Patagonia and the Galapagos raises the question of how island structures organise the project of coloniality. Her work on the deep south Patagonian shorelines, hinterlands, floating ice lands and in relation to the history of monoculture, science, and discovery narratives shapes important questions in relation to how future studies of coastal knowledge must strongly consider Indigenous memory (Gómez-Barris, 2017). May Joseph's investigations on the islands of the Indian Ocean littoral and their hidden histories of Lusophone, Dutch, Arab and African navigation trajectories, bring her to the theories of the Latin American decolonial approach of thinking islands as projects of decoloniality. Much of the Western and Eastern Indian Ocean was colonised by the Portuguese, along with the east coast of Latin America. The resulting post-colonial realities of living on island cities and coastal environments across the vast swath from the Atlantic Ocean through the Indian Ocean, the Arabian Sea through the Bay of Bengal through the Malacca Straits to the South China Seas, present a trans-oceanic connectivity of decolonial processes that demand a move away from a nationally driven articulation of belonging and history towards a more interwoven, matrixed network of coastal societies and their colonial histories (Joseph, 2019). These shared concerns exceed the national and the geographic confines of area studies (Ludden, 1999) and move us towards a comparative orientation of oceanic and island intimacies (Lowe, 2015). Merging two oceanic constructs, that of the Atlantic and the Indian Ocean, a wide lens of oceanic ontologies congeals around island structures, presenting themselves as the new knowledge making sites of climate change. As island researchers whose work seek to probe what lies under the sea, as Gómez-Barris (2017) observes, we

Shima <www.shimajournal.org > ISSN: 1834-6057 
present here a far-flung group of researchers whose work push the boundaries between land, sea and history. What precipitating histories of these oceans are archipelagoes contending with now, we ask (Joseph, 2019). Through textured collaboration that has ranged from reading together, organising a conference on archipelagos, reading each other's work, and working in the Global South Center, our research culminates in this special issue, an effort to centre the work of Indigenous scholars, decolonial thinkers, poets and artists, and their oceanic imaginations as a way towards comparative archipelagic studies.

The consideration of island coastlines in formerly and continually colonised societies is a growing area of archipelagic theorisation. As Sumathi Ramawamy (2004) demonstrates in her meticulous tracing of the role of islands in the colonial imaginary, island ecologies outside of Anglo European cartography have been historically produced as fabulations of loss, such as the lost island of Lemuria. Ramaswamy's study indicates the ontological challenges of decolonial island studies, from mythic fabulations to the periphery of national imaginaries, as many island societies have found themselves in the post-independence phase.

The island cartographies presented in this volume range with respects to their dependent relations. From the Marshall Islands, Malta, The Philippines, Chiloé and Greenland, to the islands of Guåhan/Guam, Puerto Rico and Hawai'i, in the United States, all have been thoroughly inscribed by the spectre of colonialism. Consider the fact that Indonesia, the largest island nation in the world, only got independence in 1945. India gets independence in 1947. Most Caribbean island nations became independent in the 196os. Fiji acquires independence in 1970, while the Philippines' neocolonial relationship with the United States has fractured the unraveling of its decolonial options, as Virgilio Rivas points out (Rivas, 2019). Yet "independence" is a normative framework since many of the island spaces discussed in this issue continue to contend with the political and economic fragmentation and social inequalities produced out of the ongoing experience of coloniality (Schwartz, 2019; Alvarez et al, 2019; Otto et al, 2019). We need to consider the temporal and spatial coordinates of the histories of island spaces as comprised of a multichronic and fragmented colonial optic. Ideas such as the detour, the counter story (Aikau and Gonzalez, 2019), sociotechnical imaginaries (Otto et $\mathrm{al}, 2019$ ) and the atoll-based wave perspective that incorporates an intersection of ocean, dry land and sky (Schwartz, 2019), are all models that experiment with such rethinking. The contributors in this collection offer methodologies and approaches whose decolonial possibilities reside in fully accounting for these histories as well as imagining that all is not lost as the seas continually rise.

In an influential paper written in 1948, the historian J.S. Furnivall maps out the colonised state of island cultures across the British, Spanish, Portuguese, Dutch, French and American dependencies during the late 1940s (Furnival, 1948). What is noteworthy is Furnivall's mapping of the Dutch dependencies of Java alongside Fiji, the South Sea Islands and Japan, articulated as highly segregated colonial island societies divorced from the coast and already incorporated into the global economic trading markets. In Furnivall's accounting, the tropical Far East, East Africa, West Africa and Pacific Islands comprise of a series of island economies with plural features but not plural society in the $1940 \mathrm{os}$.

Expanding on the nation-building agendas of the post-colonial state in South Asia, David Ludden points out that the focus of states such as Burma (now Myanmar) and India on their interior spaces, centred around the political centres of authority - shaped a land-based 
history of societies with extensive littoral societies such as Indian and Myanmar (Ludden, 1999). This political hegemony further marginalised the role of island cultures and the process of decolonising coastal spaces in formerly colonised societies such as Burma and India. This peripheralisation of archipelagic cultures such as those of the Rohingyas in Myanmar, the Sunderban regions of Bangladesh, and the vast coastal communities along the Coromandel Coast, the Malabar Coast and the Western coast of India, has created a geography of archipelagic forgetting in the interest of nation formation (Joseph, 2019).

III

In 'Island Studies as a Decolonial Project' Yaso Nadarajah and Adam Grydehøj (2016) lay the groundwork for the ontological and epistemological study of ocean impact on human and nonhuman worldings:

There are, of course, differences and tensions among figures and movements that advance the decolonial turn, pointing to a diversely interpreted set of positions. These positions, however, share a view of coloniality as a fundamental problem in the modern (as well as postmodern and information) age. The task of decolonisation remains unfinished, and is perhaps unfinishable. (2016: 440)

Nadarajah and Grydehøj argue for the spheres of island living as sites of the decolonial processes. Drawing on Walter Mignolo's thinking around the "decolonial option" - they draw a critical connection between decoloniality as a complex web of interlocking economies, political geographies, ontologies, and the history of islands.

This Coloniality and Islands issue of Shima offers avenues of decolonial thinking emerging out of indigenous island scholarship shaping new relationships of understanding and knowledge making. It also draws critical decolonial scholarship on island futures into making new geographic linkages, foregrounding older historic processes conveniently erased in the era of rapacious overdevelopment. What are the old and new economies linking geographical disparate islands such as Puerto Rico (Garriga-López, 2019), the Marshall Islands and Greenland (Faris, 2019)? What techniques of mnemonic traces, what communicative mechanisms of knowledge do island communities draw on to reconstruct erased histories (Perez, 2019; Aikau and Gonzalez, 2019)? How might we begin to approach a multi sited island study of historically far flung island societies to thread tenuous connectivities shaping new island relationalities (Garrison, 2019)? These are some of the questions this issue on Coloniality and Islands sets out to interrogate. To study islands is to already be immersed in a decolonial methodological engagement (Gómez-Barris, 2018; Joseph, 2019). What are some of the knowledge-making approaches this particular group of inquiries throw up for consideration?

On Governors Island, in New York's Upper Bay, sits a plaque that states that Notten Eylant as it was known to the Dutch, or Nutten Island as it was named by the British, was bought from the Lenape by the Dutch for two axe heads and a handful of white beads. The mythic sale frames the island's thousand-year documented history of indigenous habitation and ways of life that have been buried over with macadam and landfill (Cantwell and diZerrega Wall, 2003). Its former oyster shell filled shoreline is now a stark contour of military grade bulkhead stones and storm surge barriers. What strikes one after the initial charm of 
approaching Governors Island, is how the island was systematically de-islanded in its urban planning through its military grid structure imposed on a meandering landscape, reinforcing the isolationist logic of its islandness (Baldacchino, 2004). Walking along the peripheries of the island's topography, one experiences the ecological contours of the island's colonial estrangement from its archipelagic surroundings. Deliberately cut away for the first two hundred years of colonial history, and later during its military usage, Governors Island is unexpectedly connective with other Dutch islands around the world used for military forts and strategic colonial incursions. Governors Island connects to locations such as Cochin, Galle, Cape Town and Djakarta, also former Dutch colonial entrepots. Suddenly the Indian Ocean is in the Hudson River, floating in the New York harbor at once provincial and of the world (Joseph, 2013). Gesturing to the anthropogenic impact of colonial history on shorelines and coastlines around the planet, Governors Island links disparate colonial histories and geologies into emergent networks of shared concerns for climate justice. It offers a historical perspective on aquatic archaeologies, where old bays and coves have been paved over or filled in to create modern landscapes. Filled with the remnants of the colonial maritime hub, the island implicitly offers navigational residues reminiscent of colonial fort islands around the world (Joseph, 2013).

Writing from an archipelago whose individual islands have very distinctive histories of theft and colonisation, the question of indigenous landscapes, settler decoloniality, reclamation of indigenous coastal ecologies, and the methodologies in unpacking rooted networks has forged unexpected solidarities beyond the New York archipelago (Nirmal, 2016). We are beginning to understand how the shifting physicality of island spaces such as those of Guåhan/Guam and Puerto Rico, of Hawaii and the Marshall Islands intersect with the aquapelagic formations of New York City (Hayward, 2012; Aikau and Gonzalez, 2019; Garrison, 2019; Perez, 2019; Faris, 2019; Alvarez et al, 2019; Guerin, 2019; Joseph, 2013). New York's varied island topographies. comprising of estuary islands, land filled islands, artificial coastlines, reclaimed mudflats and barrier islands, allow for a complex and interwoven series of studies regarding the intersection of coloniality and island ontologies.

\section{V}

New York is an assemblage of Lenape, Dutch, British and US histories of island becoming. It has absorbed and morphed through centuries of occupation, indigenous oppression, and the forging of diasporic island communities across its different boroughs. The Lenape continued to live in the Rockaway Islands and in the barrier islands of the Canarsie region of New York City during the Dutch occupation of New Amsterdam. During the 180os, a broadening demographic of coastal communities from around the world such as the Greeks, the Irish, the Sicilians, the Syrians and West Indians, occupied the coastal regions of Brooklyn, the Bronx and Queens. Consequently, New York's coastal history is deeply transoceanic, as noted in its physical design along South Street Seaport and Hanover Square. Embossed on the pedestrian walkway across Hanover Square are all the ports, islands and cities that traded with New York over its maritime history. The actual cataloging of islands onto the ground of New York today at Hanover Square marks its seafaring narrative as central to the formation of the city itself. If one had to locate a place from which to embark on a trans-oceanic theory of crossings and ecological rethinking of islands across diachronic temporalities, New Amsterdam, or New York as it has come to be known, would be one such node to trace the "submerged perspectives" of imperialism and coloniality, of slavery and its legacies, through an exploration of decolonial methods (Gómez-Barris, 2017; Joseph, 2019). 
Ayasha Guerin's essay on Black marine entanglements around New York's coast dexterously foregrounds these diachronic temporalities, what she calls the "risky assemblages of being" (Guerin, 2019: 50). Guerin lays out the littoral of New York, the interface of land and sea across its islands, as a zone of interspecies dependence, between Black littoral workers, Black activisms and aquatic life. She identifies precarity as a condition of existence bolstered by the labours of Black oystermen. Guerin unfurls the intersections of race, nature and capital that marked the landfilled and low-lying reaches of the New York aquapelago (Guerin, 2019). Her historical analysis of the junctures of resource extraction, racial enclosures and economic exclusions sheds light on just how insidiously the geography of islands and the production of social stratification commingled. The waterfront in Guerin's writing is an active space of Black fugitivity in the 19th Century. According to Guerin, understanding the historical conditions of the production of New York's littoral is necessary for an attenuated resilient thinking that can incorporate the varieties of coastal being today.

\section{VI}

Aikau and Gonzalez ask how might one begin to articulate the heterogeneity of coastal beings shaping island ecologies today (Aikau and Gonzalez, 2019). Otto, Nimführ and Bieler on the other hand, unpack the legal and ontological difficulties that such heterogeneity of island becoming generates (Otto et al, 2019) in the face of slavery, immigration, displacement and forced migrations. Remembering minoritarian, Black and Indigenous spaces of labor and industry as part of the matrix of sea edges is key to unlocking this question of heterogeneity for island economies, Guerin argues (Guerin, 2019). Such an exercise is however, complicated by Rebekah Garrison's notion of an archipelagic imperialism that shapes the waters of United States, not just around New York but into the Pacific as part of an ongoing colonial condition for island peoples (Garrison, 2019). Garrison observes that islands across the Caribbean, Pacific, Atlantic and Indian Oceans were already colonised by white settlers by the end of the 19th Century and, like Guerin, calls for a renewed political rigour around settler responsibility in US island relations. The term "settler responsibility", which Garrison coins, is premised on a critical world view that shapes decolonial exchanges across the complexities and uneven histories of archipelagic imperialism. For Aikau and Gonzalez, Perez, Schwartz, Faris, Garrison and Alvarez et al, finding Indigenous concepts from Hawaiian, Chamorro, Carolinian, Marshallese and Puerto Rican cultures opens a dialogue about ethical responsibilities with respects to formerly colonised sites (Aikau and Gonzalez, 2019; Perez, 2019; Schwartz, 2019; Faris, 2019; Garrison, 2019; Alvarez et al, 2019). We concur that this is an urgent way forward towards the engaged praxis of a decolonial future.

Garrison observes that islands have been, and continue to remain, the foci of imperial impulses. Yet, this spatial imperative is also hidden offshore from the US Empire, creating a violent thickness of colonisation within territories. Garrison's (2019) persistence that settler communities have a responsibility that is global in scope because US militarisation is expansionist, is a reflexive call rooted in the belief that an ethics of solidarity with Indigenous peoples is the decolonial gesture (Gómez-Barris, 2017) that could begin a narrative of accountability.

"Kuleana is a right and entitlement bestowed upon the indigenous peoples of the Pacific Islands to carry the knowledge and memories within the seascape... All of humanity has a kuleana to the ocean" writes Karen Amimoto Ingersoll (2016: 153). Ingersoll argues for a

Shima Volume 13 Number 22019 
seascape epistemology grounded in practice and education. It is a conceptual ocean gathering pedagogy where Epeli Hau'ofa's "sea of islands" (Hau'ofa, 1994) flows into the spaces of community culture, knowledge and sea becoming. Calling for indigenous oceanic literacies, Ingersoll calls for a sensational and experiential seascape epistemology where the rain, sea, salt, wind and clouds fuses with a social science of the oceans around the islands of the Pacific. Ingersoll's call for an oceanic literacy is embraced by a number of contributions in this issue, in a search for indigenous remembrances, decolonial ocean-body assemblages through poetry (Perez, 2019), film (Faris, 2019) and artistic deflections (Aikau and Gonzalez, 2019). These multi genre immersions in Ingersoll's notion of a seascape epistemology open up neglected connectivities, emergent associations and sources of power rooted in native ontologies. They are counter reactions to the notion of "island sojourns" (Gillis, 2007) that have shaped histories of formerly colonised island spaces. The writings offered here grapple with centuries of erasure. They struggle to articulate alternative cosmologies, erased memories of oceanic becoming grounded in island potentialities. They expose the entrenched economies of coloniality that accompanied the idyllic white settler narratives of island occupations around the world.

"It is important to pursue a decolonial island studies that rethinks the ways in which island development research can end up marginalising Indigenous voices at the same time as it seeks to understand islands 'on their own terms" writes Adam Grydehøj (2017:3). Grydehøj's point is well taken, but for many island locales, the first order excavation of what a seascape epistemology might look like is still to be undertaken. The Malabar and Western coasts of South Asia, for instance, have been surprisingly neglected as specific assemblages by contemporary historians and theorists of South Asia (Joseph, 2019; Swaminathan, 2015). As Grydehøj observes, Island Studies has not succeeded in addressing the complex interstices of coloniality and postcoloniality when thinking about islands. Furthermore, some geographical regions have remained largely unimpacted by island studies scholarship, as in the case of South and Southeast Asia, Russia and China (Grydehøj, 2017).

VIII

In the field of Island Studies, the move away from reading islands as static island forms towards a relational and archipelagic approach (Pugh, 2018) has opened up complex models for rethinking frameworks of island ontologies. Extracting island colonial histories from systems of big data produces new information patterns and new networked relations that absorb island realities. Adapting theoretical lenses to grapple with the algorithms and the material production of infrastructures that produce, sustain and generate island ecologies is part of the challenge for decolonial methodologies. This entails inventing nuanced and innovative ways of sensing relations that are both the cause and opportunity for a decolonial island praxis. Referring to Bratton's 2016 notion of "The Stack", a megastructure that has coalesced as both a technological and geopolitical system, Jonathan Pugh observes, that "The Stack is not only calculative; it is geological, sociological, economic, chemical and geopolitical ... the proliferation of new sensing techniques is of importance to island studies in the Anthropocene" (Pugh, 2018: 101). Again Pugh, "the transformative logics of digital technology today are playing a key role in how islands and relationality, and the unfolding temporalities of the Anthropocene, are reworked, understood and engaged" (ibid).

This Coloniality and Islands issue demonstrates how the notion of the stacked (Bratton, 2016) or layered impact of colonialism on island futures disrupts conceptions of peripherality (Otto et al, 2019; Schwartz, 2019; Aikau and Gonzalez, 2019), periodicity (Aikau and Gonzalez, 2019; Faris, 2019; Alvarez, 2019) temporality (Rivas, 2019) and proliferates

Shima Volume 13 Number 22019 
"zones of epistemic deprivation and dependency" (Schwartz, 2019: 120). The case study presented by Alvarez et al (2019) on the indigenous practices of fishing weirs around the Interior Sea of Chiloé offers a tangible instance of how indigenous knowledge-making habitats survive. The fishing weirs around Chiloé's marginal sea demonstrate a fragile but resilient example of how insular cosmologies materialise through "a particular form of cohabiting with non-human species in island spaces.” (Alvarez et al, 2009: 159).

Otto, Nimführ and Bieler (2019) present the case of immigrant citizenship in Malta as a highly complex, stacked system of understanding how colonial histories, island ecologies and migration patterns over centuries are generating new sensing economies (Otto et al, 2019). They refer to it as the "socio-technical imaginary", which in the case of Malta, is a carceral framework. Multiple colonial legacies over centuries have influenced how contemporary Maltese immigration policies are being implemented. The Maltese case demonstrates effectively Pugh's demand that digital technologies are propelling islands and relationality today in unprecedented ways. Understanding nomadic and migrant citizenship (Joseph, 1999) in Malta involves disentangling the complex laws and regulations that small island states such as Malta have with the European Union. Drawing on immersive, longterm ethnographic techniques, Otto, Nimführ and Bieler present a striated, highly mediated system of legal procedures through which refugees and migrants into the EU find themselves trapped in, when they arrive or sojourn in Malta.

This issue on Coloniality and Islands emerged as a collaboration towards a praxis of planetary decolonial feminisms (Maese-Cohen, 2010). Writing, co-writing, editing each other's work, teaching, creating curriculum, performing on islands around New York, walking the archipelagic city, studying the coastline, retracing the pathways of Lenape ecologies, our seascape epistemologies have slowly shaped a kuleana (an act of caring and respect for land) which is an engagement with other island dwellers across the living archipelago of New York City, an imagined islandness of over forty floating bodies of mud, sand, wetlands and volcanic schist. This edited issue is also a kuleana with decolonial scholars around the world embedded within islands whose histories of colonisation have robbed them of memories, place and futures (Aikau and Gonzalez 2019, Schwartz, 2019, Otto et al, 2019). We embrace the idea of the kuleana as a way of ecologically engaging with the histories of the past and the present, a practice of becoming awake in states of settler responsibility, as Rebekah Garrison entreats us to educate ourselves into becoming. This archipelagic futurity is a methodological reconstituting of "life anew" (Lugones, 2007).

It is a challenge to think through how we, as beneficiaries of settler colonialism might responsibly occupy space on indigenous territory, as well as a call to apply an oceanic literacy to our understanding of the history of coloniality and islands under imperialism. Rethinking the vast repositories of island colonialisms and their aftermath on island populations offers a window into what Vandana Shiva (1996) calls "ontological vulnerability" - a sphere where the circle of rights is expanding and the domain of responsibility is shrinking. It is a space of confusion, forgetting and ecological degradation.

IX

At the United Nations Climate Change Conference in Bonn, 2017 - the small island nation of Fiji presided over the convention. It was the first time that a small island nation was nominated to head the 23rd Conference of Parties (COP) held under the Framework of the United Nations' 1992 Convention on Climate Chang and signalled the precarious positions

Shima Volume 13 Number 22019

-7 - 
of small island communities around the world. At COP 23, 197 countries acknowledged the vulnerability of islands. The geopolitical precarity of small island nations, autonomous island territories and island protectorates are vastly different in issues and scope, as the essays in this special issue underscore. The degree of dependency and vulnerability shift as the histories of these formerly colonised island territories morph.

The case of Malta, at the heart of Europe and the Mediterranean presents the contradicting burdens of statehood and regional integration for small island states. Malta is the only country in the European Union (EU) which was colonised multiple times. It is also an independent state within the EU with national regulations as well as EU regulations that affect any immigrant on arrival. Hence the stack logic of multiple regulations impacting migrants from Africa. The socio technical imaginaries influencing how histories of colonialism affect refugees entering the small island nation are particularly instructive (Otto et al, 2019). Drawing on a different set of oceanic ontologies - those of the Pacific and the Atlantic - the cases of Hawai'i, Guåhan/Guam and Puerto Rico present settler colonial histories through which notions of islandness and coloniality are explored in this issue (Aikau and Gonzalez, 2019; Garrison, 2019; Perez, 2019; Faris, 2019). The peculiar position of the US vis a vis the Marshall Islands, where the Marshallese are non-immigrants but not citizens of the United States, produces yet another relationship of extractive labor that small island territories with sovereignty are subjected to (Schwartz, 2019; Faris, 2019). The archipelagic structures of Chiloé and the Philippines (Alvarez et al, 2019; Rivas, 2019) respectively present yet a different set of structuring patterns of power differentials through marginal seas and colonial histories. The two case studies respectively demonstrate how efforts to reclaim lost histories are being remapped onto archipelagic knowledge productions locally.

As critical voices from across some of the most vulnerable small island states in the world, this edited volume emphasises that decolonial island methodologies need to account for layers of colonial affect on future island theorising.

\section{BIBLIOGRAPHY}

Aikau H and Gonzalez V.V (2019) 'Curating a Decolonial Guide: The Detours Project', Shima v13 n2: 11-21

Álvarez R, Munita D, Mera R, Borlando I, Ther-Rios F, Nunez D and Hayward P (2019) 'Rebounding from Extractivism. The history and re-assertion of traditional weir-fishing practices in the Interior Sea of Chiloé', Shima v13 n2: 155-173

Baldacchino, G (2004) 'The Coming of Age of Island Studies', Journal of Economic and Social Geography v5 n3: 272-283

Bratton, B.H (2016) The Stack: on software and sovereignty, Cambridge: MIT press

Cantwell, A and diZerrega Wall, D (2001) Unearthing Gotham: The Archaeology of New York. New Haven: Yale University Press

Faris J.H (2019) 'Sisters of Ocean and Ice: On the hydro-feminism of Kathy Jetnil-Kiljner and Aka Niviana's Rise: From One Island to Another', Shima v13 n2: 76-99 
Furnivall, J.S (1948) Colonial policy and practice: a comparative study of Burma and Netherlands India, Cambridge: Cambridge University Press

Garriga-López, A (2019) 'Puerto Rico: the future in question', Shima v13 n2: 174-192

Garrison, R (2019) 'Settler Responsibility: Respatialising Dissent in “America” Beyond Continental Borders', Shima v13 n2: 56-75

Gillis, J.R 'Island Sojourns’ Geographical Review v97 n2: 274-287

Gómez-Barris, M (2017) The Extractive Zone: Social Ecologies and Decolonial Perspectives, Durham: Duke University Press

----- (2018) Beyond the Pink Tide: Art and Political Undercurrents in the Americas, Berkeley: University of California Press

Guerin, A (2019) ‘Underground and at Sea: Black Marine Entanglements in New York's ZoneA', Shima v13 n2: 30-55

Grydehøj, A (2017) ‘A future of island studies' Island Studies Journal v12 n1: 3-16

Hau'ofa, E (1994) 'Our Sea of Islands', The Contemporary Pacific v6 n1: 148-61

Hayward, P (2015) 'The Aquapelago and the Estuarine City: Reflections on Manhattan', Urban Island Studies n1: 81-95

Ingersoll, K.A (2016) Waves of Knowing: A Seascape Epistemology, Durham: Duke University Joseph, M (1999) Nomadic Identities: The Performance of Citizenship, Minneapolis: University of Minnesota Press

----- (2019) Sea Log: Indian Ocean to New York, London: Routledge

Lowe, L (2015) Intimacies of Four Continents, Durham: Duke University Press

Ludden, D (2005) Making India Hindu: Religion, Community, and the Politics of Democracy in India, London: Oxford University Press

Lugones, M (2007) 'Heterosexualism and the Colonial/Modern Gender System' Hypatia v22 n1: 186-209

Maese-Cohen, M (2010) 'Introduction: Toward Planetary Decolonial Feminisms', Qui Parle v18 n2: 3-27

Nadarajah, Y and Grydehøj, A (2016) 'Island studies as a decolonial project', Island Studies Journal v11 n2: 437-446

Nirmal, P (2016) 'Being and Knowing Differently in Living Worlds: rooted Networks and Relational Webs in Indigenous Geographies,' in Harcourt, W (ed) The Palgrave Handbook of Gender and Development, London: Palgrave Macmillan: 232-250 
Otto, l, Nimführ, S and Bieler, P (2019) 'Preserving Maltese Identity in Refugee Management: On the Emergence and Absence of a Prison Spatiality', Shima v13 n2: 135-154

Perez, C.S (2019) 'Guåhan, The Pacific and Decolonial Poetry’, Shima v13 n2: 22-29

Pugh, J (2018) 'Relationality and Island Studies in the Anthropocene', Island Studies Journal v13 n2: 93-110

Ramaswamy, S (2004) The Lost Land of Lemuria: Fabulous Geographies, Catastrophic Histories, Los Angeles and Berkeley: University of California Press

Rivas, A.V (2019) 'Mapping a People to Come: Lessons from stressed islands and island assemblages in archipelagic Southeast Asia and other transversals', Shima v13 n2: 100-115

Schwartz, J (2019) 'Waves of Displacement and Waves of Development: Marshallese Songfest competitions and cultural diplomacy in Springdale, Arkansas', Shima v13 n2: 116134

Shiva, V and Moser, I (1996) Biopolitics: A Feminist and Ecological Reader on Biotechnology, Hyderabad: Orient Longman

Swaminathan, R (2015) 'Ports and Digital Ports: The Narrative Construction and Social Imaginaries of the Island City of Mumbai', Urban Island Studies nı: 35-54 